Article

\title{
Smart Multi-Sensor Monitoring in Drilling of CFRP/CFRP Composite Material Stacks for Aerospace Assembly Applications
}

\author{
Roberto Teti $^{1,2, *}$, Tiziana Segreto ${ }^{1,2}(\mathbb{D})$, Alessandra Caggiano ${ }^{2,3}$ and $^{-}$Luigi Nele ${ }^{1}$ \\ 1 Department of Chemical, Materials \& Industrial Production Engineering, University of Naples Federico II, \\ Piazzale Tecchio 80, 80125 Naples, Italy; tsegreto@unina.it (T.S.); luigi.nele@unina.it (L.N.) \\ 2 Fraunhofer Joint Laboratory of Excellence on Advanced Production Technology (Fh J_LEAPT UniNaples), \\ Piazzale Tecchio 80, 80125 Naples, Italy; alessandra.caggiano@unina.it \\ 3 Department of Industrial Engineering, University of Naples Federico II, Piazzale Tecchio 80, \\ 80125 Naples, Italy \\ * Correspondence: roberto.teti@unina.it
}

Received: 17 December 2019; Accepted: 10 January 2020; Published: 21 January 2020

check for updates

\begin{abstract}
Composite material parts are typically laid out in near-net-shape, i.e., very close to the finished product configuration. However, further machining processes are often required to meet dimensional and tolerance requirements. Drilling, edge trimming and slotting are the main cutting processes employed for carbon fiber-reinforced plastic (CFRP) composite materials. In particular, drilling stands out as the most widespread machining process of CFRP composite parts, chiefly in the aerospace industrial sector, due to the extensive use of mechanical joints, such as rivets, rather than welded or bonded joints. However, CFRP drilling is markedly challenging: due to CFRP abrasiveness, inhomogeneity and anisotropic properties, tool wear rates are inherently high leading to superior cutting forces and detrimental effects on workpiece surface quality and material integrity. Damage such as delamination, cracks or matrix thermal degradation is often observed as the result of uncontrolled tool wear or improper machining conditions. Sensor monitoring of drilling operations is, therefore, highly desirable for process conditions' optimization and tool life maximization. The development of this kind of automated control technologies for process and tool state evaluation can notably contribute to the reduction of scraps and tool costs as well as to the improvement of process productivity in the drilling of CFRP composite material parts. In this paper, multi-sensor process monitoring based on thrust force and torque signal detection and analysis was applied during drilling of CFRP/CFRP laminate stacks for the assembly of aircraft fuselage panels with the scope to evaluate the tool wear state. Different signal-processing methods were utilised to extract diverse types of features from the detected sensor signals. A machine-learning approach based on an artificial neural network (ANN) was implemented to make smart decisions on the timely execution of tool change, which is highly functional for CFRP drilling process automation.
\end{abstract}

Keywords: stack drilling; CFRP/CFRP laminates; multiple sensor monitoring; tool wear evaluation

\section{Introduction}

In the aerospace industry, weight reduction is critical to meet environmental requirements (lower emissions) and to reduce management costs (lower fuel consumption). The use of advanced composite materials such as carbon fiber-reinforced plastics (CFRP) is increasing ever more due to their exceptional performance in terms of high specific strength and stiffness, excellent corrosion resistance, and good fatigue resistance $[1,2]$. 
In the new generation of aircraft, the percentage of CFRP composite materials has significantly increased, reaching in some cases over $50 \%$ of the whole weight of the vehicle. This trend is going to continue in the near future [3].

The assembly of CFRP composite parts is most frequently carried out using mechanical joints, such as rivets, due to the difficulty of realizing welding operations, only applicable to thermoplastic matrix composites, or adhesive joints. Accordingly, drilling is the most widespread CFRP machining process in the aerospace and aeronautical industries. As a matter of fact, in a medium-sized airplane some 85,000 rivets are estimated [4,5]. Drilling of CFRP laminates is frequently carried out manually and cutting tools are often replaced largely before the end of tool life to avoid material damage due to early tool failure [6]. This has a quite negative effect on the cost and productivity of drilling operations.

Nevertheless, drilling of CFRP composite parts is a challenge for manufacturing engineers due to the anisotropic nature of the material, the rapid tool wear caused by abrasive carbon fibers, and the highly concentrated stresses and vibrations. These phenomena may cause critical defects affecting material integrity, surface quality and part acceptability: hole entry and hole exit delamination, geometrical and dimensional errors, interlaminar delamination, fiber pullout, and thermal damage [7-9]. In past decades, diverse non-destructive testing and evaluation techniques were developed and applied to detect defects for quality evaluation of CFRP components $[8,10,11]$.

Delamination, i.e., the separation of laminated layers, is the most critical damage mode since its presence negatively impacts the hole strength and consequently the in-service behaviour of assembled parts [12-14].

The delamination phenomenon is closely influenced by the drilling process parameters [15-20]. In [21,22], an excessively high thrust force is reported as the main process parameter responsible for catastrophic tool failure and extended delamination damage.

Previous studies have shown that delamination usually occurs at hole entry, due to the so called "peel-up" phenomenon, and hole exit, due to the so called "push-out" phenomenon, along the drilled hole periphery $[4,23]$. The influence of the thrust force for push-out delamination is very high compared to the effect of torque [7].

The optimization of drilling conditions includes the optimal selection of cutting speed and feed rate as well as the thrust force value obtained. Feed rate affects the onset of delamination more severely than spindle speed: in [24], it is shown that minimum peel-up and push-out delamination is verified at minimum feed rate value. However, using too low a feed rate, an increase of contact time between tool and workpiece is generated causing possible thermal damage to the composite material [25].

A higher automation of drilling processes for assembly applications would certainly enhance the productivity of assembly procedures but it needs an effective and dependable drilling process control to ensure hole quality and to fully exploit tool life. A solution can be represented by the development of robust and reliable on-line real-time process control techniques.

In this paper, smart multi-sensor process monitoring based on thrust force and torque signal detection and analysis was applied during drilling of CFRP/CFRP laminate stacks for the assembly of aircraft fuselage panels with the scope to evaluate the tool wear state. Different signal-processing methods were utilised to extract diverse types of features from the detected sensor signals in the time domain, in the frequency domain, and using fractal analysis. A machine-learning approach based on artificial neural network (ANN) data processing was implemented using selected signal features to make smart decisions on the timely execution of tool change, which is highly functional for CFRP drilling process automation, on the basis of tool wear level estimation and tool wear curve reconstruction.

\section{Materials and Experimental Procedures}

The CFRP/CFRP laminate stacks for the drilling experimental program were made of two overlaid, symmetrical and balanced CFRP laminates of $5 \mathrm{~mm}$ thickness (Toray T300 carbon fibers, CYCOM 977-2 epoxy matrix). Each laminate had 26 unidirectional plies with stacking sequence $[ \pm 452 / 0 / 904 / 0 / 90 / 02] \mathrm{s}$. 
A thin $0 / 90$ fabric fiberglass/ epoxy ply was laid on the top and the bottom surfaces of each laminate. The CFRP laminate fabrication was performed by hand layup, vacuum bag moulding, and autoclave cure for $180 \mathrm{~min}$ at $180^{\circ} \mathrm{C}$ under 6 bar pressure.

In the CFRP/CFRP stack, the laminates were overlaid with their bag sides in contact, representing the severest stack drilling condition (Figure 1). Drilling tests of CFRP/CFRP stacks were performed on a $\mathrm{CNC}$ drill press with a clamping system designed to reproduce the industrial drilling operation conditions for assembly of aircraft fuselage panels (Figure 2).

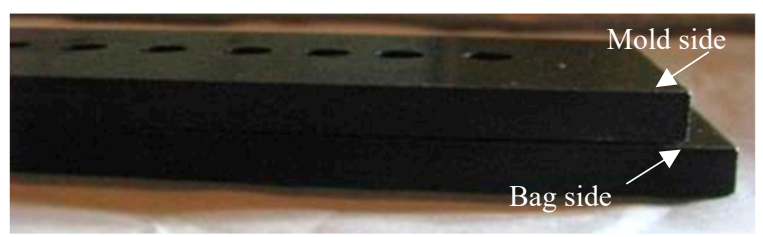

Figure 1. Carbon fiber-reinforced plastic (CFRP)/CFRP laminate stack for drilling experimentation: mold side (smooth surface); bag side (irregular surface).

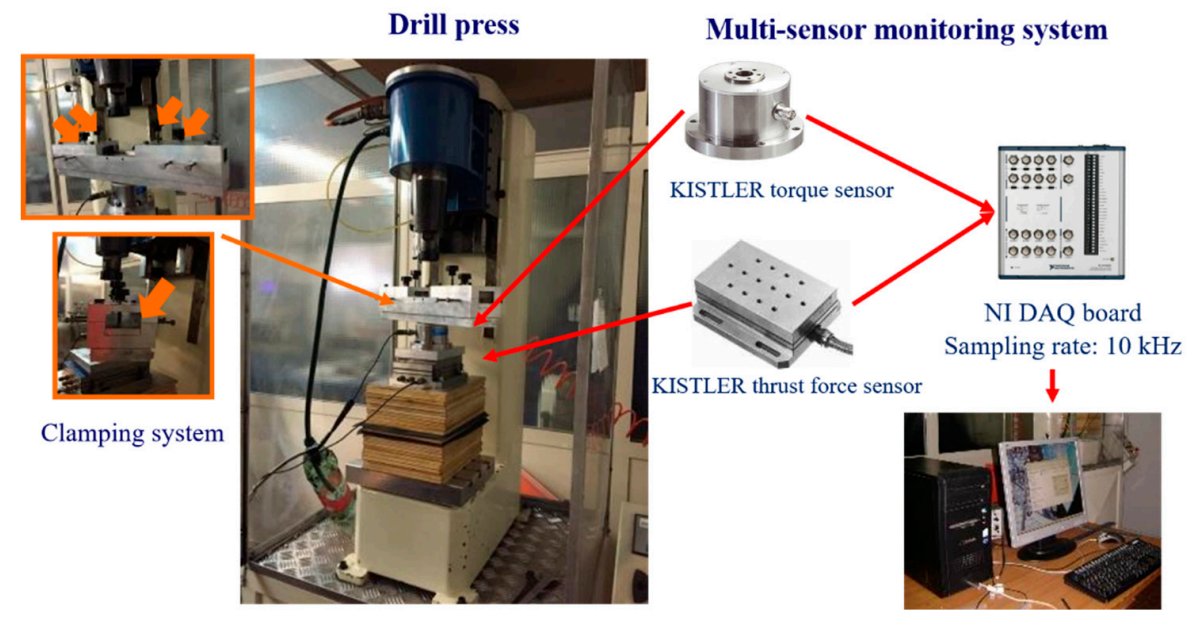

Figure 2. Experimental set-up of CFRP/CFRP stack drilling.

The cutting tools were drill bits made of tungsten carbide with the typical characteristics of twist drills utilised in the aeronautical industry: diameter: $\mathrm{D}=6.35 \mathrm{~mm}$; geometry: step/twist; point angle: $120^{\circ} / 125^{\circ}$; helix angle: $20^{\circ} / 30^{\circ}$.

The process conditions utilized for stack drilling were: feed rate $=0.11-0.15-0.20 \mathrm{~mm} / \mathrm{rev}$; spindle speed: 2700-6000-9000 rpm (Table 1).

Table 1. Experimental drilling conditions.

\begin{tabular}{cccc}
\hline & Spindle & Speed & rpm \\
\hline $\begin{array}{c}\text { Feed rate, } \\
\mathbf{m m} / \mathbf{r e v}\end{array}$ & 2700 & 6000 & 9000 \\
0.11 & $\mathrm{X}$ & $\mathrm{X}$ & $\mathrm{X}$ \\
0.15 & $\mathrm{X}$ & $\mathrm{X}$ & $\mathrm{X}$ \\
0.20 & & $\mathrm{X}$ & \\
\hline
\end{tabular}

For each experimental condition, a sequence of 60 holes was realized with the same drill bit.

During the drilling tests, a piezoelectric dynamometer (Kistler 9257) was employed to acquire the thrust force along the $\mathrm{z}$-direction, $\mathrm{F}_{\mathrm{z}}$, and a torque dynamometer (Kistler 9277A25) was utilized to acquire the cutting torque about the $\mathrm{z}$ axis, T. As shown in Figure 2, the torque sensor was mounted under the drilling samples clamping system and the thrust force sensor was installed immediately 
under the torque sensor. The acquired analogue sensor signals were digitalized by a DAQ board (NI USB-6361) at $10 \mathrm{kHz}$ according to the Nyquist-Shannon sampling theorem.

\section{Tool Wear Measurement}

An optical measuring machine (Tesa Visio V-200, Figure 3) was used to measure the tool flank wear, VB (mm), according to ISO 3685 standard [26]. The drilling tools were fixed on a clamping system (Figure 3) in order to assure the repeatability of the measurement procedure. The VB measurements were carried out at D/6 from the external tool diameter, $\mathrm{D}$, on the left and right cutting edges after every 10 drilled holes (Figure 4).

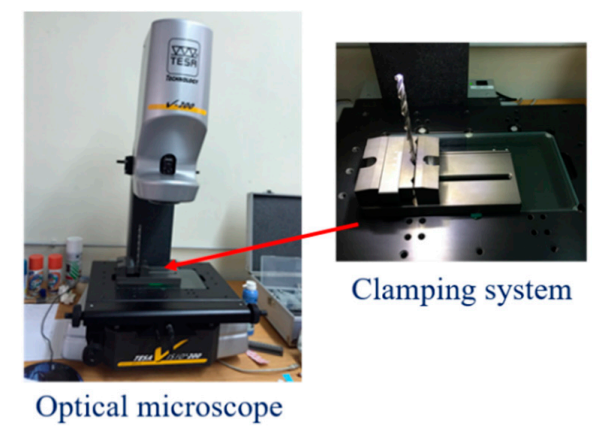

Figure 3. Optical measuring machine and drilling tool clamping system for tool wear measurement.

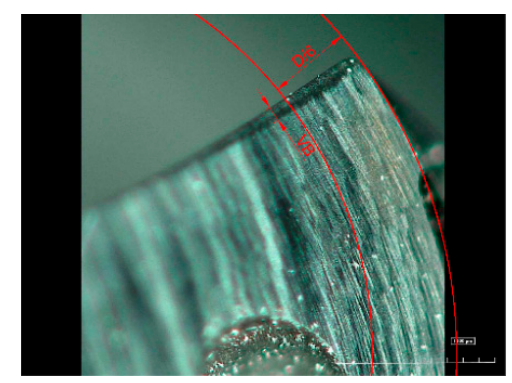

Figure 4. Magnified view of cutting lip and flank wear measurement.

The measured flank wear values were reported in Figure 5 for diverse drilling conditions, highlighting a rising trend in the evolution of tool wear for all operating conditions. A third-order polynomial interpolation of the measured VB values was applied for tool wear curve construction under the different drilling conditions in order to look for correlations between the actual tool wear level and the features extracted from the sensor signals.

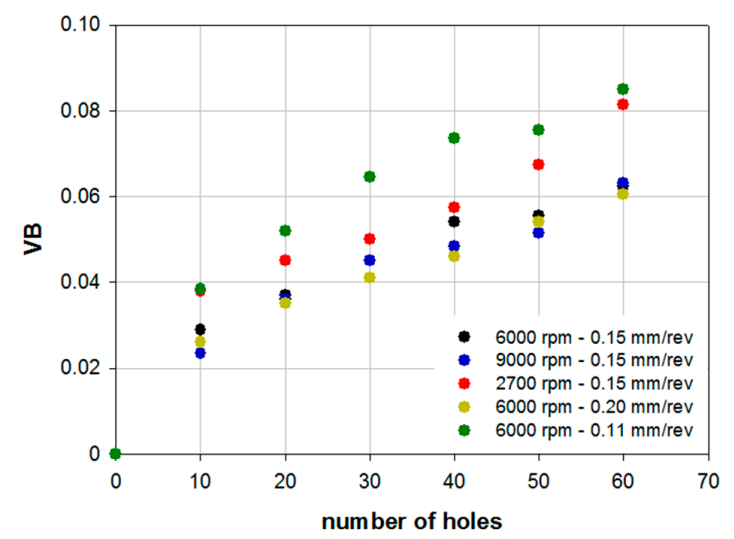

Figure 5. Measured flank wear VB vs. hole number for diverse drilling conditions. 


\section{Sensor Signal Analysis}

\subsection{Morphology of Sensor Signals}

The thrust force and torque signals acquired during CFRP/CFRP stack drilling are greatly scattered with presence of high-frequency oscillations (Figure 6): this behaviour is strongly related to the anisotropic nature of CFRP laminates [27]. Previous studies on cutting of CFRP materials disclosed that the fiber orientation with respect to the cutting direction determines the mechanism of chip formation and the cut surface quality [28,29]. Thus, different cutting modes can be identified based on the angle formed between cutting edge and reinforcing fibers, also known as fiber cutting angle (Figure 7) [28]. During unidirectional CFRP drilling, the fiber cutting angle varies continuously with drill rotation, determining different mechanical loading and surface quality conditions (Figure 8) [29]. The case of multidirectional CFRP laminate drilling is even more complex: not only the fiber cutting angle varies during drill rotation, but also different cutting modes occur at the same time along the cutting edge, according to the diverse fiber orientations of the multiple plies simultaneously cut by the cutting edge (Figure 9). High-amplitude oscillations in the force and torque signals during drilling of multidirectional CFRP laminates are the sum of multiple waves with a phase difference depending on the different fiber orientations $\left(0^{\circ}, 45^{\circ}, 90^{\circ},-45^{\circ}\right)$ and an amplitude related to the number of plies with same fiber orientation simultaneously cut by the cutting edge.

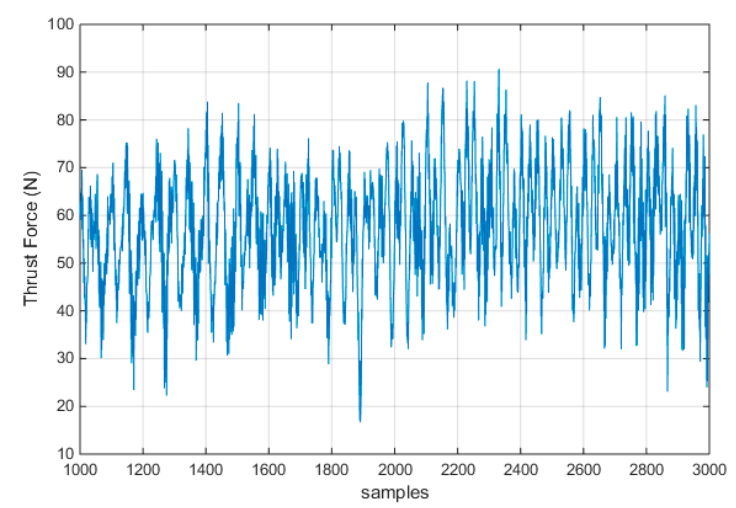

Figure 6. Trust force high frequency signal oscillations (6000 rpm-0.15 mm/rev) [27].

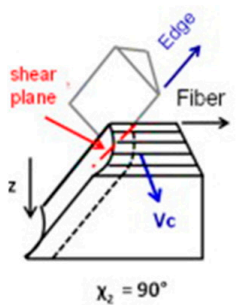

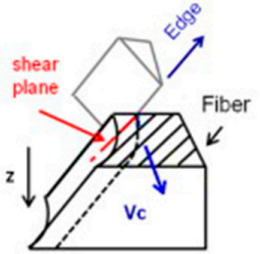

$x_{2}=45^{\circ}$

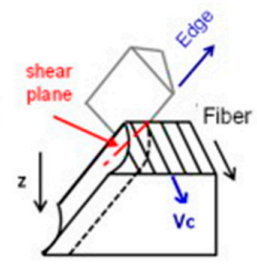

$x_{2}=0^{\circ}$

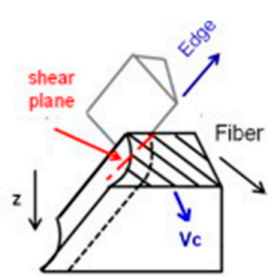

$x_{2}=-45^{\circ}$

Figure 7. Fiber cutting angle during drilling [28].
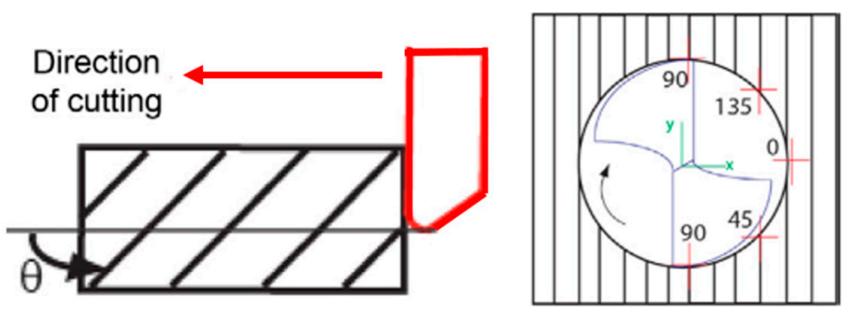

Figure 8. Variation of fiber cutting angle during drilling [29]. 


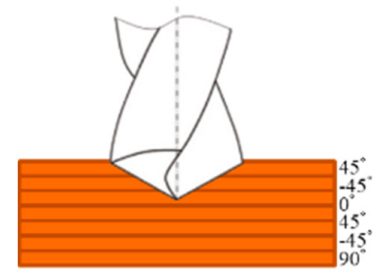

Figure 9. Diverse simultaneous fiber orientations along the cutting edge.

\subsection{Sensor Signal Pre-Processing}

The raw thrust force and torque sensor signals acquired during the drilling tests included signal portions corresponding to time periods before and after real machining. With the aim to extract sensorial information only when the tool is actually removing material, a signal segmentation procedure was performed on the thrust force signals and synchronically extended to the torque signals. The identification of the start and end of the actual machining portion of the signal was carried out on the basis of thresholds set on the moving average of the thrust force signals.

In Figure 10, the thrust force signal segmentation for hole $\mathrm{n}^{\circ} 6$ with drilling parameters $6000 \mathrm{rpm}$ and $0.15 \mathrm{~mm} / \mathrm{rev}$ is reported, showing a drop of thrust force at the interface between the two laminates which are in contact with their bag sides characterized by very irregular surfaces.

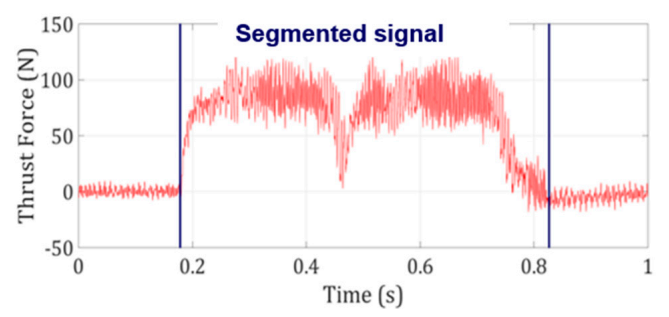

Figure 10. Thrust force segmented signal ( $6000 \mathrm{rpm}-0.15 \mathrm{~mm} / \mathrm{rev}$, hole $\left.\mathrm{n}^{\circ} 6\right)$ : no real machining occurs before and after the segmented signal [27].

In Figure 11, the thrust force signals are reported versus the increasing number of holes (from 1 to 60) for the operating conditions $2700 \mathrm{rpm}-0.15 \mathrm{~mm} / \mathrm{rev}$ showing that the thrust force and its variance significantly grows with increasing number of holes (ranging from $50 \mathrm{~N}$ for hole $\mathrm{n} .1$ to over $200 \mathrm{~N}$ for hole n.60). Figure 12 shows the torque signals versus the number of holes for $2700 \mathrm{rpm}-0.15 \mathrm{~mm} / \mathrm{rev}$ drilling conditions highlighting the same previous behaviour.

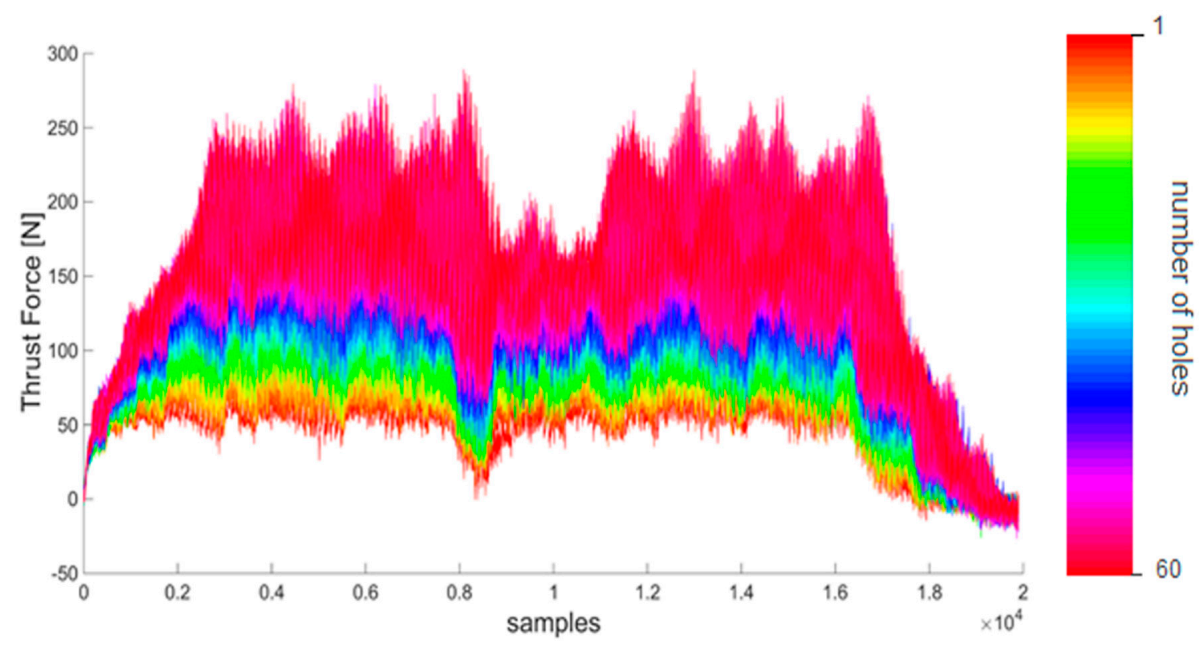

Figure 11. Segmented thrust force signals vs. number of holes (2700 rpm-0.15 mm/rev). 


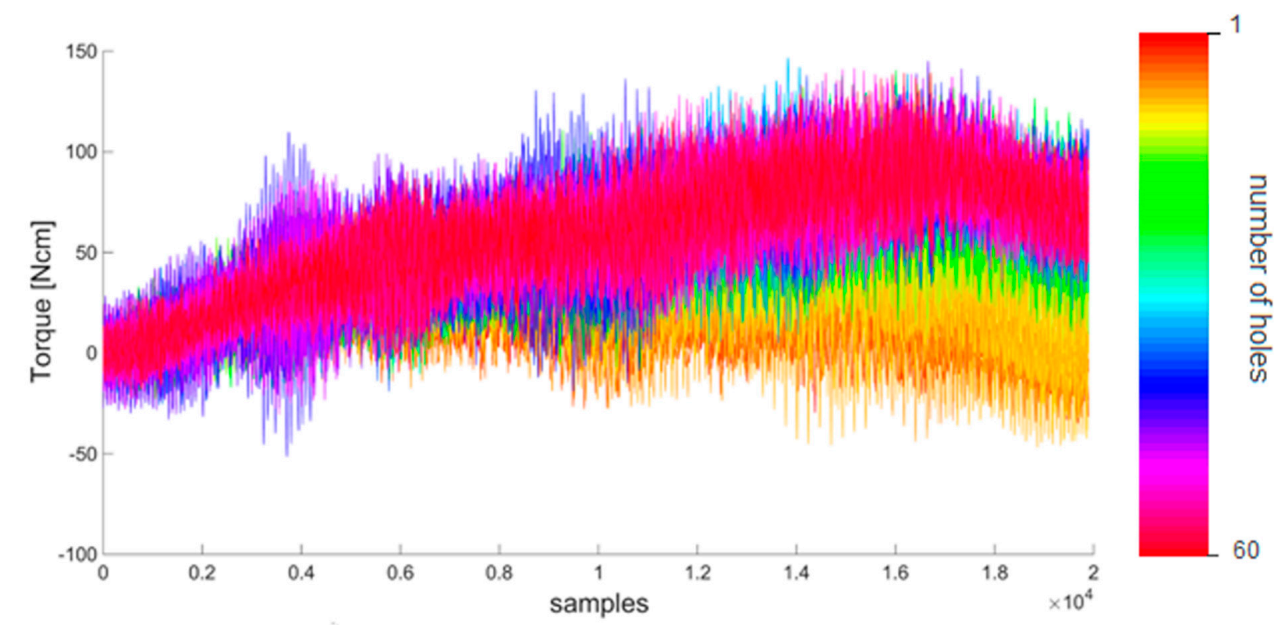

Figure 12. Segmented torque signal vs. number of holes (2700 rpm-0.15 mm/rev).

\section{Sensor Signal Feature Extraction}

Different signal processing methods were applied to extract diverse types of signal features from the segmented thrust force and torque signals:

- Time domain signal features

- Frequency domain signal features

- Fractal analysis signal features

The extracted signal features were then subjected to selection procedures aimed at identifying those with the highest relation with tool wear level. The selected features were used for the construction of feature pattern vectors (FPV) to be fed as input to ANN-based machine-learning paradigms in order to make decisions on the timely execution of drilling tool change.

\subsection{Signals Feature Extraction in the Time Domain}

Statistical features in the time domain were extracted from the segmented thrust force and torque signals: arithmetic mean $\left(\mathrm{F}_{\text {mean }}, \mathrm{T}_{\text {mean }}\right)$, variance $\left(\mathrm{F}_{\mathrm{var}}, \mathrm{T}_{\mathrm{var}}\right)$, skewness $\left(\mathrm{F}_{\text {skew }}, \mathrm{T}_{\text {skew }}\right)$, kurtosis $\left(\mathrm{F}_{\text {kurt }}\right.$, $\mathrm{T}_{\text {kurt }}$ ), signal energy $\left(\mathrm{F}_{\text {ene, }}, \mathrm{T}_{\text {ene }}\right)$. Some of these features displayed a good correlation with hole number and thus, expectedly, with tool wear level. In Figure 13, as an example, statistical features extracted from the thrust force signals are plotted for all operating conditions vs hole number up to the last hole $n^{\circ} 60$. From the figure, it can be noticed that some of the features increase with increasing number of holes while other features decrease with growing hole number. In general, by carrying out a graphical analysis of feature trends, higher or lower degrees of correlation with hole number is verified as a function of the specific statistical feature.

\subsection{Signals' Feature Extraction in the Frequency Domain}

A fast Fourier transform (FFT) was applied to convert the segmented thrust force and torque signals into the frequency domain. For both thrust force and torque signals, relevant frequency peaks were found corresponding to $1 \times-2 \times-3 \times-4 \times-5 \times-6 \times$ the drill bit revolution frequency.

Figure 14 show the FFT of thrust force signals for the drilling test performed at $6000 \mathrm{rpm}$ and $0.15 \mathrm{~mm} / \mathrm{rev}$, in which the revolution frequency is $6000 \mathrm{rpm} / 60=100 \mathrm{~Hz}$. The highest frequency peaks were observed at $100,200,300,400,500,600 \mathrm{~Hz}$, i.e., at $1 \times-2 \times-3 \times-4 \times-5 \times-6 \times$ the revolution frequency. 
(a)
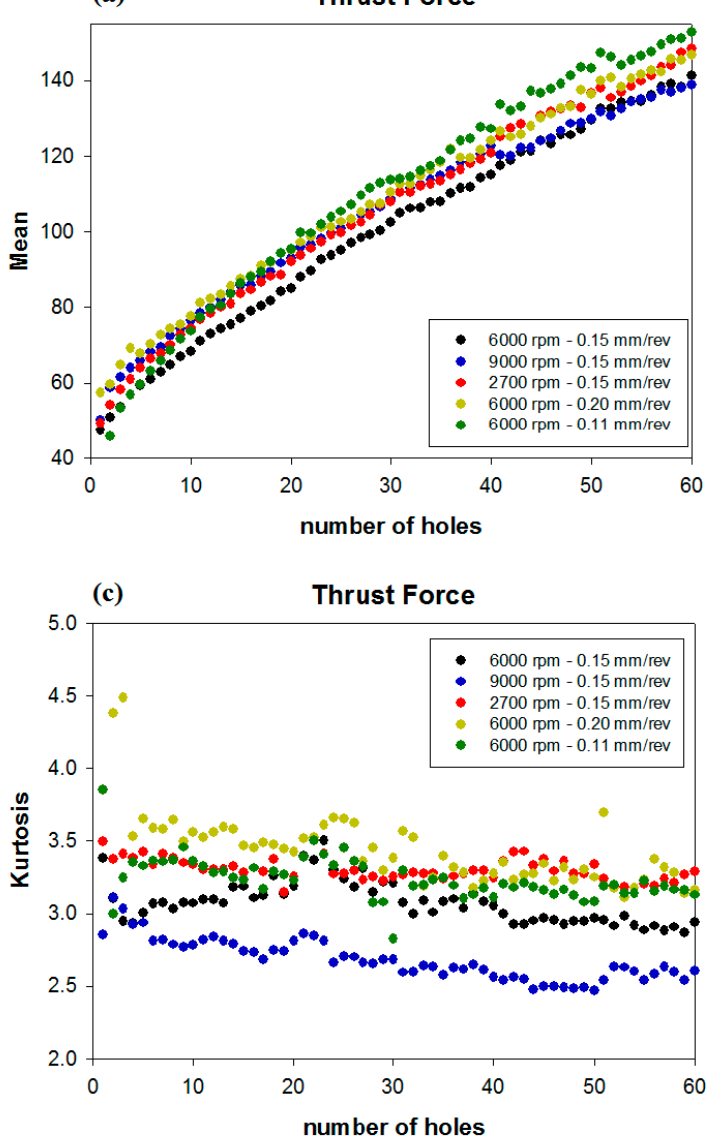

(b)
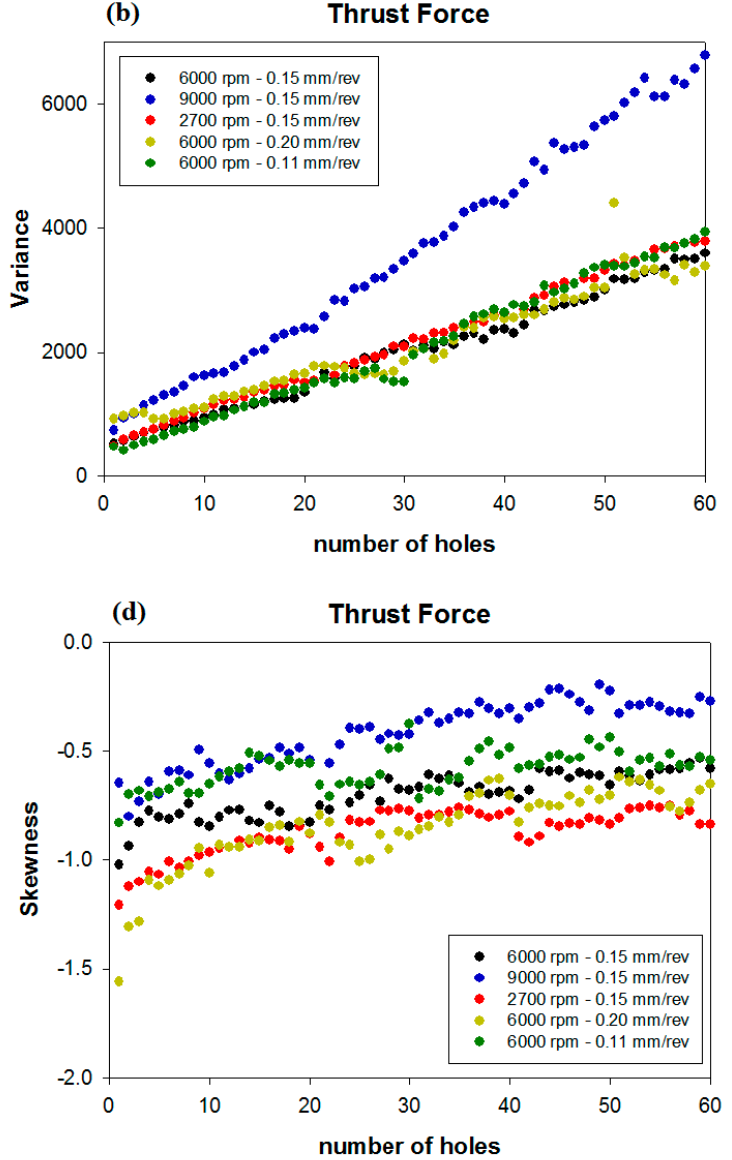

Figure 13. Statistical features extracted from the thrust force signals for all operating conditions vs. hole number: (a) arithmetic mean; (b) variance; (c) kurtosis; (d) skewness.

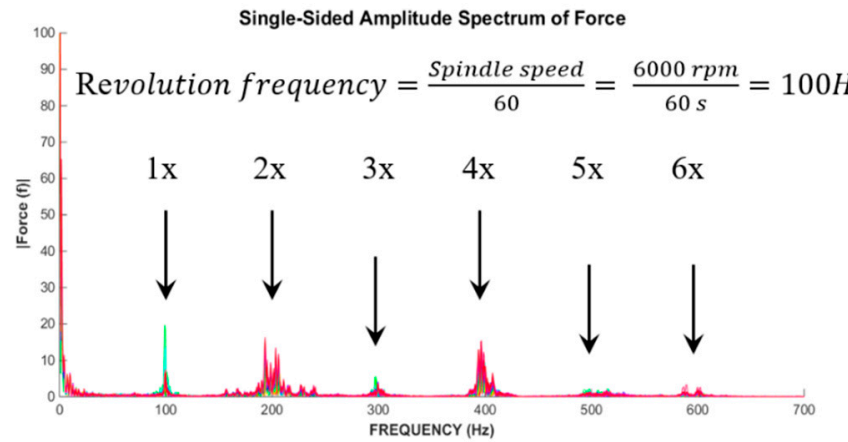

Figure 14. Thrust force signal single-sided amplitude spectrum (6000 rpm-0.15 mm/rev) [27].

In Figure 15, the frequency peaks of the thrust force signal are reported versus hole number for the drilling test performed at $6000 \mathrm{rpm}$ and $0.15 \mathrm{~mm} / \mathrm{rev}$. It can be observed that the amplitudes of some of the frequency peaks grow with increasing number of holes, suggesting a potential correlation of the frequency peak amplitude with tool wear progression. 


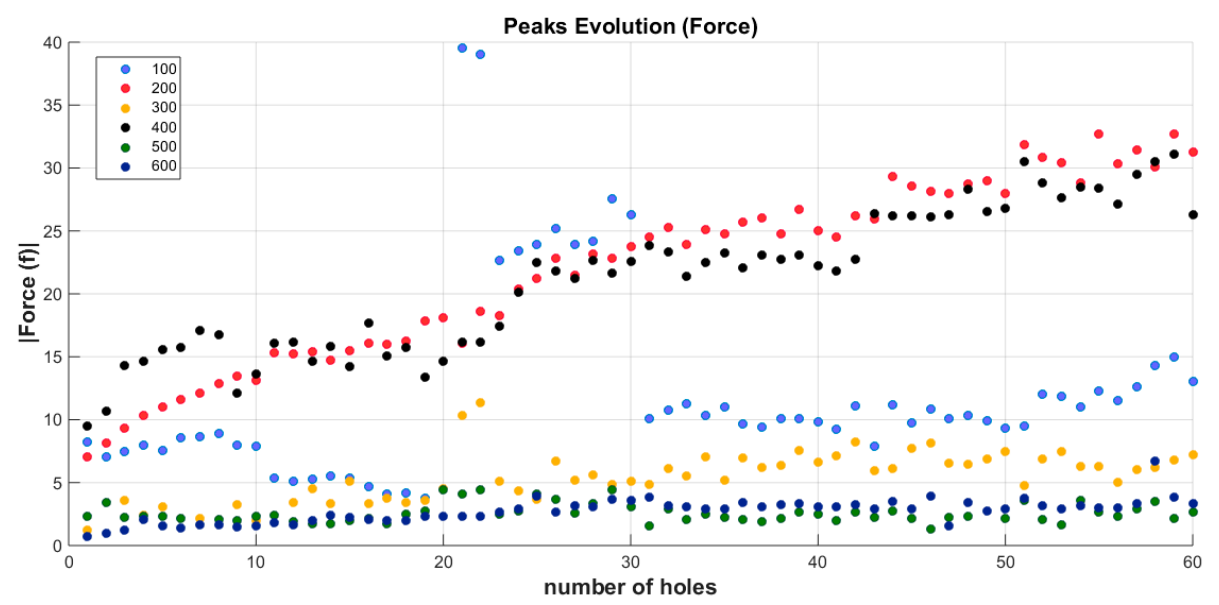

Figure 15. Frequency peaks of the thrust force vs. hole number (6000 rpm-0.15 mm/rev) [27].

\subsection{Fractal Analysis Signal Features Extraction}

An innovative signal processing approach based on fractal analysis was applied to carry out feature extraction from the segmented thrust force and torque signals.

Fractals were introduced by the mathematician Benoit Mandelbrot to describe the length of Britain's coastline [30]. Nowadays, a fractal is seen as an object which owns a self-affine pattern or singularity. Several applications of fractal analysis were presented in the literature. In metrology, fractal analysis has been investigated and effectively applied to define the roughness of surfaces [31]. As a matter of fact, mathematicians found that rough surfaces have a self-affine behaviour and used the fractal dimension to estimate its roughness [32]. On the other hand, only few research articles show interest in applying this analysis technique in machining, such as for the analysis of sensor signals detected during machining process monitoring.

In this research work, the objective of fractal analysis is to quantify the changes in complexity and shape of the drilling sensor monitoring signals along the tool life. Using regularization fractal analysis, based on convolutions of sensor signals with kernels of different types (rectangular kernel and Gaussian kernel), two sets of curves were built [33]. Two examples of regularization analysis graphs obtained using the rectangular kernel and the Gaussian kernel are displayed in Figure 16 where the different colours refer to the different hole numbers. It can be observed that the regularization curves are influenced by the tool wear level (Figure 16a): they become increasingly bumpy, with higher and more marked arches as the hole number grows.

In order to adapt the analysis to the machining process under study, the regions to extract the fractal parameters were selected based on the tool rotational speed. Two regions, Region 1 and Region 2, were identified in the regularization analysis graphs for the rectangular kernel (Figure 16a) and a third region, Region 3, for the Gaussian kernel (Figure 16b). The boundaries of Regions 1 and 3 were set so as to keep low $a$ values and hold a sufficient number of points for linear regression to extract the slope from the graph curve. The boundaries of region 2 were positioned in order to extract information from the graph arches.

For each region, three fractal parameters were extracted: the slope, $D$, which represents the fractal dimension quantifying the signal complexity; the $y$-intercept, $G$, quantifying the signal ruggedness; and the $R$-square, $R^{2}$, quantifying the auto-scale regularity in the selected region. 


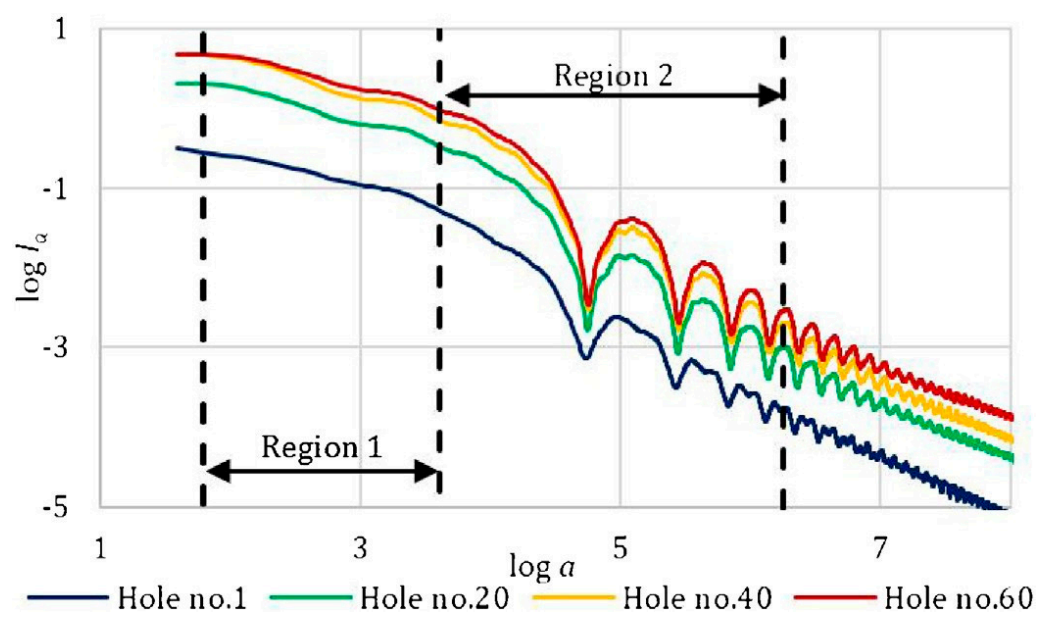

(a)

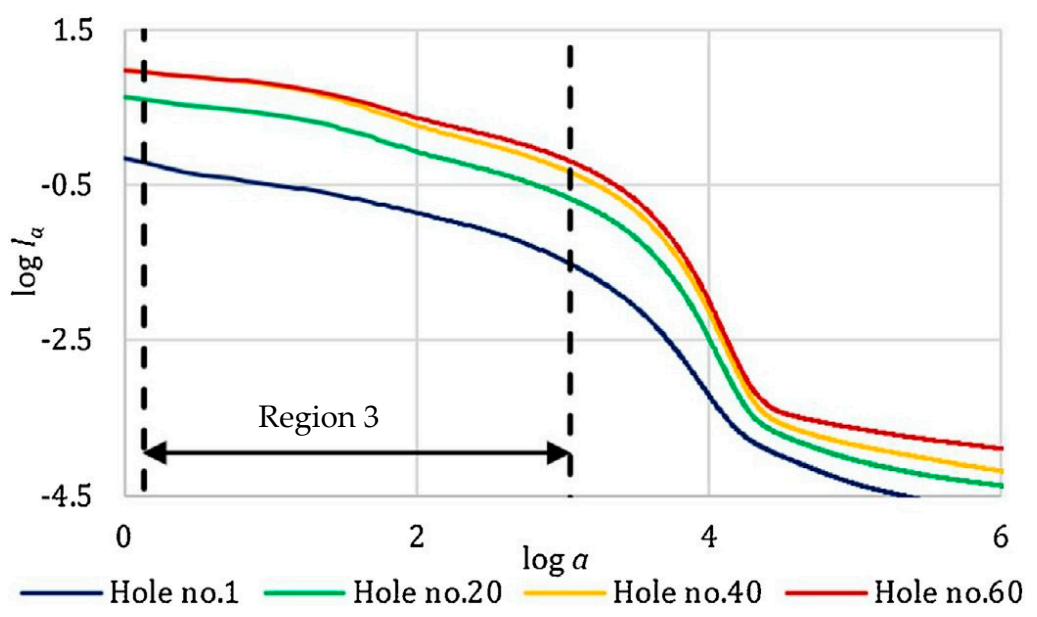

(b)

Figure 16. Regularization analysis curves: (a) rectangular kernel; (b) Gaussian kernel [33].

\section{Features Selection for Pattern Feature Vector Construction}

A statistical approach was employed to evaluate the correlation between segmented time domain, frequency domain and fractal features, on the one hand, and the measured tool flank wear values, on the other hand, using the Spearman correlation coefficient, $\mathrm{r}_{\mathrm{s}}$ :

$$
r_{s}=\frac{\operatorname{cov}\left(r g_{X}, r g_{Y}\right)}{\sigma_{r g_{X}} \sigma_{r g_{Y}}}
$$

where $\operatorname{cov}\left(r g_{X}, r g_{Y}\right)$ is the covariance of the rank variables (i.e., $r g_{X}=$ features values, $r g_{Y}=$ tool flank wear values) and $\sigma_{r g_{X}} \sigma_{r g_{Y}}$ are the standard deviations of the rank variables.

If $0<r_{s}<0.3$, the correlation is weak; if $0.3<r_{s}<0.7$, the correlation is adequate; if $0.7<r_{s}<1$, a strong correlation occurs. Based on the $\mathrm{r}_{\mathrm{s}}$ value, the features displaying the highest correlation with tool wear level were selected as follows:

- Time domain features-Three features were selected from the thrust force signals: thrust force average $\left(\mathrm{F}_{\text {mean }}\right)$, thrust force variance $\left(\mathrm{F}_{\mathrm{var}}\right)$ and thrust force kurtosis $\left(\mathrm{F}_{\text {kurt }}\right)$, and one feature was selected from the torque signal: torque average $\left(\mathrm{T}_{\text {mean }}\right)$. All these featuers displayed a strong correlation with tool wear level. 
- Frequency domain features-The following set of features was selected: Fpeak2x, Fpeak4x, Fpeak6x, Tpeak2x, and Tpeak4x. The first three features, extracted from the thrust force signal, displayed the highest correlation with tool wear level.

- Fractal analysis features-Three fractal features were selected from the thrust force signal: the $G$ parameter in region $1\left(\mathrm{~F}_{\mathrm{G} 1 \mathrm{R}}\right)$, the $G$ parameter in the Gaussian region $\left(\mathrm{F}_{\mathrm{G}-\mathrm{G}}\right)$, the Index in region $2\left(\mathrm{~F}_{\text {Index,2R }}\right)$, exhibiting a strong correlation with tool wear. From the torque signal, one fractal feature was selected: the $G$ parameter in the Gaussian region $\left(\mathrm{T}_{\mathrm{G}-\mathrm{G}}\right)$, showing an adequate correlation with tool wear level.

The Spearman correlation coefficient was utilized in order to select the features displaying the highest robustness in identifying the tool flank wear level. Accordingly, the selected time domain, frequency domain, and fractal features were used to construct sensor fusion pattern vectors (FPV), containing features from thrust force and torque signals to be then employed for tool wear diagnosis through ANN based machine learning. In particular:

- For time domain, a FPV was constructed containing the selected statistical features of thrust force and torque signals plus the hole number: $\mathrm{FPV}_{\text {time }}=\left[\mathrm{F}_{\text {mean }}, \mathrm{F}_{\mathrm{var}}, \mathrm{F}_{\text {kurt }}, \mathrm{T}_{\text {mean }}, \mathrm{H}_{\mathrm{n}}\right]$

- For frequency domain, a FPV was constructed containing the selected features of thrust force and torque signals: $\mathrm{FPV}_{\text {freq }}=\left[\right.$ Fpeak $_{2 \mathrm{x}}$, Fpeak $_{4 \mathrm{x}}$, Fpeak $_{6 \mathrm{x}}$, Tpeak $_{2 \mathrm{x}}$, Tpeak $\left._{4 \mathrm{x}}\right]$

- For fractal analysis, a FPV was constructed containing the four selected fractal features of thrust force and torque signals plus the hole number: $\mathrm{FPV}_{\text {fract }}=\left[\mathrm{F}_{\mathrm{G} 1 \mathrm{R}}, \mathrm{F}_{\mathrm{G}-\mathrm{G}}, \mathrm{F}_{\text {Index,2R }}, \mathrm{T}_{\mathrm{G}-\mathrm{G}}, \mathrm{H}_{\mathrm{n}}\right]$

\section{Machine Learning Based on Artificial Neural Network (ANN) Data Processing}

The constructed time domain, frequency domain and fractal analysis FPV were used as input to ANN based machine learning paradigms for tool wear curve reconstruction aiming at optimal tool life exploitation. Machine learning is an artificial intelligence method based on the idea that machines can learn from data, allowing complex models to be built that can make diagnoses, forecasts or decisions from example data inputs by revealing the patterns embedded in data [34,35]. In this paper, three-layer cascade-forward back propagation ANN were built with diverse configurations, one for each drilling test condition. The architecture of a cascade forward ANN is made of input, hidden and output layers, and comprises connections from the input to each network layer, and from each layer to the successive layers. The input layer collects input patterns while the output layer provides classifications to which input patterns may map [36].

For each drilling test condition, 60 input-output vectors, one for each drilled hole, were formed to set up the ANN learning set. The input layer received in input the selected feature pattern vector $\left(\mathrm{FPV}_{\text {time, }}, \mathrm{FPV}_{\text {freq }}\right.$, or $\left.\mathrm{FPV}_{\text {fract }}\right)$ for each drilled hole while the corresponding tool flank wear values, VB, were fed to the output layer during ANN learning.

The utilized ANN had the following architecture:

- the number of input layer nodes was equal to the number of elements of the input FPV, i.e., 5 input nodes;

- the number of hidden layer nodes was set equal to $1 x, 2 x$ or $3 x$ the number of input layer nodes, i.e., 5,10 or 15 hidden nodes;

- the output layer had only one node corresponding to the tool flank wear value, VB.

For ANN training, a Levenberg-Marquardt optimization algorithm [36] was chosen with the following parameters: maximum number of epochs: 1000; performance goal: 0 ; maximum validation failures: 6; minimum performance gradient: $1 \times 10^{-7}$; maximum mu: $1 \times 10^{+10}$; training stop: when the maximum number of epochs is reached and the maximum amount of time is exceeded.

The learning set of $60 \mathrm{FPVs}$ was partitioned into three subsets for training $(70 \%)$, validation $(15 \%)$ and testing (15\%). The training subset is utilised for calculating the gradient and updating the ANN weights and biases. The validation subset is used to avoid data overfitting by monitoring the error 
on this subset during training, so that the ANN weights and biases that correspond to the lowest validation error are stored. The testing subset is used to evaluate the performance of the trained ANN. However, the given partition into training, validation and testing subsets can significantly affect the ANN pattern recognition performance in tool wear level evaluation. For this reason, a bootstrap resampling technique was applied to randomly generate the subsets several times with the aim to enhance the estimation of the ANN pattern recognition performance [34,35]. Following the bootstrap procedure, from the original set of $60 \mathrm{FPVs}$, the training (42 FPV), validation (9 FPV) and testing (9 FPV) subsets were resampled 60 times with replacement. Thus, the overall pattern recognition performance in tool wear level evaluation for tool wear curve reconstruction was estimated by aggregating the recognition rates obtained by all 60 re-samplings.

\section{Results and Discussion}

The performance of the three-layer cascade-forward backpropagation ANN for smart tool wear curve reconstruction was evaluated using the root mean square error (RMSE):

$$
R M S E=\sqrt{\sum_{i=1}^{n} \frac{\left(\hat{y}_{i}-y_{i}\right)^{2}}{n}}
$$

where $\hat{y}_{i}$ are the ANN predicted tool flank wear values and $y_{i}$ are the measured tool flank wear values.

The ANN results obtained reveal that the 5-5-1 ANN configuration provided the lowest RMSE values for smart tool wear curve reconstruction for almost all drilling test conditions in comparison with the 5-10-1 and 5-15-1 ANN configurations. In Table 2, the RMSE values for the 5-5-1 ANN configuration are reported for each drilling condition and for the time domain $\mathrm{FPV}_{\text {time, }}$ the frequency domain $F P V_{\text {freq, }}$, the fractal analysis FPV fract. Moreover, the RMSE values obtained from a fourth FPV,

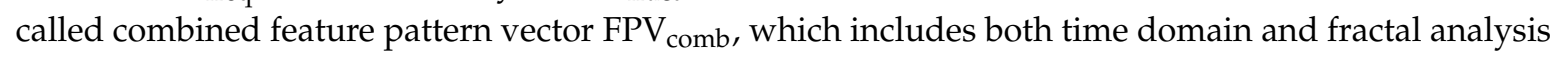
features is a sensor fusion approach, are also reported in the last column of the table.

Table 2. Performance of the 5-5-1 artificial neural network (ANN) configuration expressed as root mean square error (RMSE) in tool wear curve reconstruction for each drilling condition and each constructed feature pattern vector (FPV).

\begin{tabular}{ccccc}
\hline \multicolumn{5}{c}{ RMSE for ANN Configuration 5-5-1 } \\
\hline Drilling Condition & \multicolumn{4}{c}{ ANN Performance in Terms of RMSE for Different FPV } \\
\hline (rotational speed-feed rate) & $\mathrm{FPV}_{\text {time }}$ & $\mathrm{FPV}_{\text {freq }}$ & $\mathrm{FPV}_{\text {frac }}$ & $\mathrm{FPV}_{\text {comb }}$ \\
$2700 \mathrm{rpm}-0.11 \mathrm{~mm} / \mathrm{rev}$ & 0.00109 & - & 0.00045 & 0.00032 \\
$2700 \mathrm{rpm}-0.15 \mathrm{~mm} / \mathrm{rev}$ & 0.00407 & 0.00221 & 0.00347 & 0.00321 \\
$6000 \mathrm{rpm}-0.11 \mathrm{~mm} / \mathrm{rev}$ & 0.00249 & 0.00195 & 0.00046 & 0.00044 \\
$6000 \mathrm{rpm}-0.15 \mathrm{~mm} / \mathrm{rev}$ & 0.00514 & 0.00134 & 0.00076 & 0.00241 \\
$6000 \mathrm{rpm}-0.20 \mathrm{~mm} / \mathrm{rev}$ & 0.00061 & 0.00099 & 0.00125 & 0.00035 \\
$9000 \mathrm{rpm}-0.11 \mathrm{~mm} / \mathrm{rev}$ & 0.00328 & - & 0.00154 & 0.00083 \\
$9000 \mathrm{rpm}-0.15 \mathrm{~mm} / \mathrm{rev}$ & 0.00037 & 0.00121 & 0.00051 & 0.00034 \\
Average RMSE & 0.00244 & 0.00154 & 0.00120 & 0.00113 \\
\hline
\end{tabular}

From Table 2 and Figure 17a, it can be noted that the best overall ANN performance was obtained for drilling condition $9000 \mathrm{rpm}-0.15 \mathrm{~mm} / \mathrm{rev}$ with the lowest RMSE equal to 0.00037 , whereas the worst overall RMSE, equal to 0.00514 , was obtained for drilling condition $6000 \mathrm{rpm}-0.15 \mathrm{~mm} / \mathrm{rev}$. Both the lowest and the highest RMSE values were obtained when using the time domain feature pattern vector, $\mathrm{FPV}_{\text {time. }}$. 


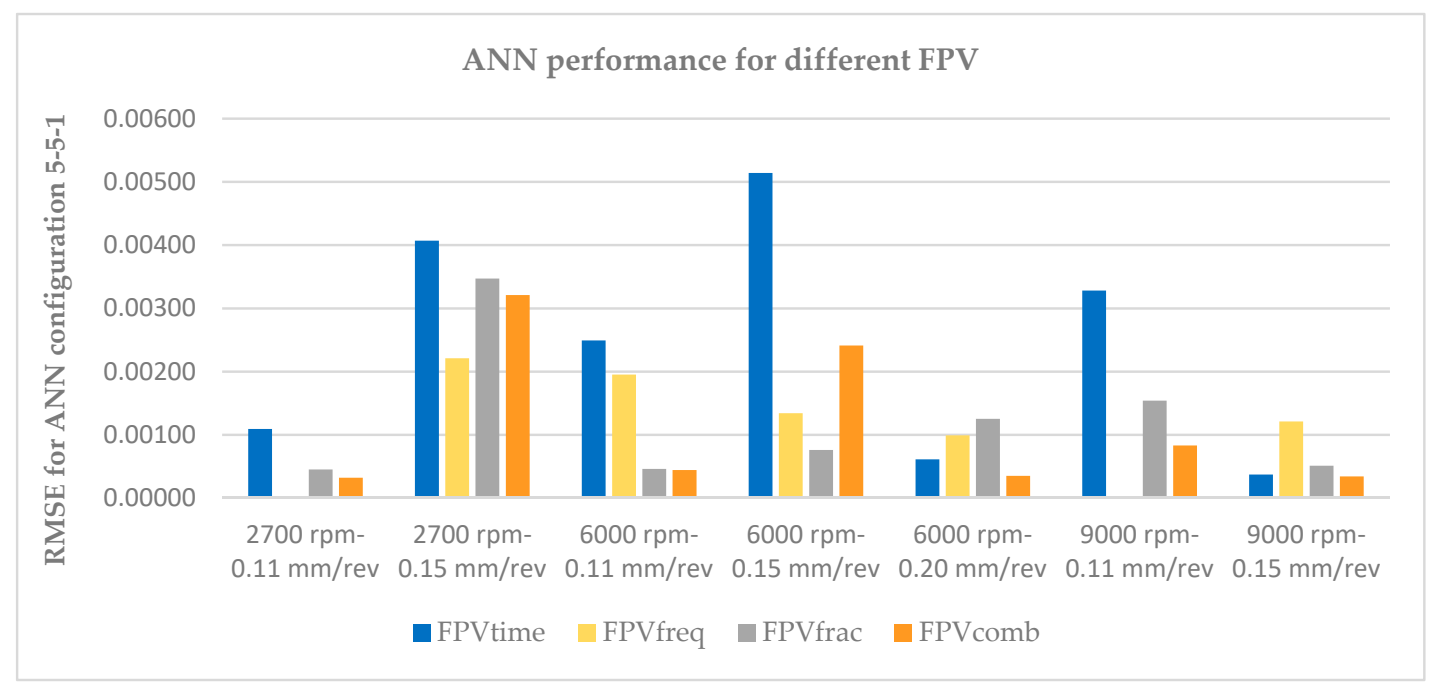

(a)

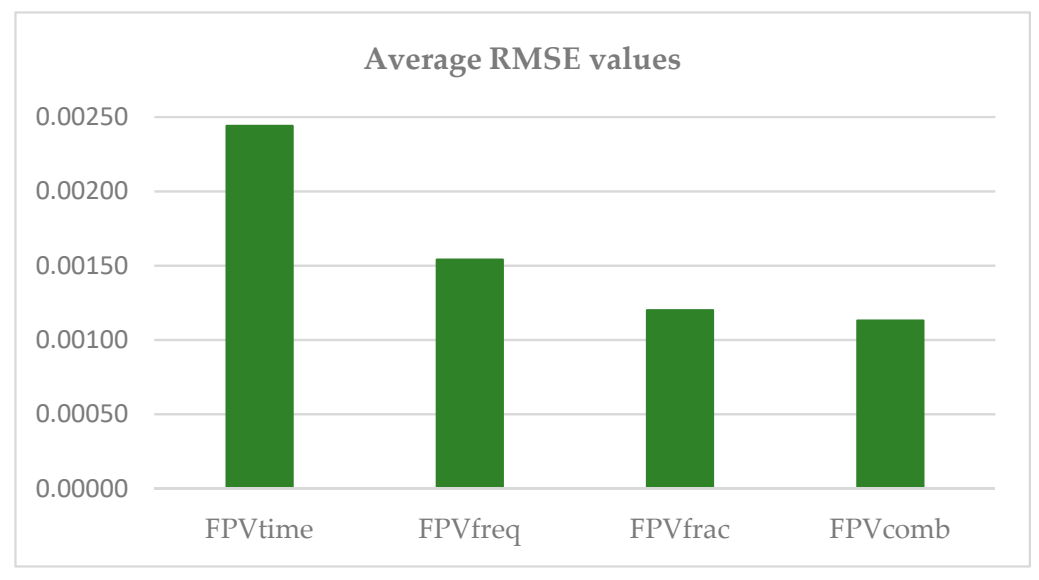

(b)

Figure 17. (a) RMSE values for the 5-5-1 ANN configuration for each drilling condition and for each constructed FPV; (b) RMSE average values for each constructed FPV.

As regards the frequency domain feature pattern vector, $\mathrm{FPV}_{\text {freq, }}$, the RMSE values ranged between 0.00099 (lowest RMSE) and 0.00221 (highest RMSE).

In the case of the fractal analysis feature pattern vector, $\mathrm{FPV}_{\text {fract }}$, the lowest RMSE was equal to 0.00045 whereas the highest RMSE was 0.00347 .

The examination of the average RMSE values, evaluated by considering the RMSE values obtained with the same given FPV applied to all the drilling conditions (Table 2 and Figure 17b), indicates that the fractal analysis $\mathrm{FPV}_{\text {fract }}$ provided the best ANN performance in the classification of tool wear level, while the time domain $\mathrm{FPV}_{\text {time }}$ came second and the frequency domain $\mathrm{FPV}_{\text {freq }}$ came third in this ranking.

Thus, to verify the robustness of smart tool wear curve reconstruction by making use of signal features obtained from diverse feature extraction methodologies, the time domain and the fractal analysis features were considered in a combined manner with the scope to construct an additional sensor fusion feature pattern vector, $\mathrm{FPV}_{\text {comb }}$. The latter was built using the two most correlated fractal analysis features, the two most correlated statistical features and the hole number: $F P V_{\text {comb }}=\left[F_{G-G}, F_{\text {Index }, 2 R}\right.$, $F_{\text {mean }}, F_{v a r}, H_{n}$ ]. This 5-component sensor fusion feature pattern vector, FPV $_{c o m b}$, was employed for the learning of the same previously utilized 5-5-1 ANN configuration. 
In the last column of Table 2, the RMSE values obtained with the 5-5-1 ANN configuration are reported for the case of the combined feature pattern vector FPV $_{\text {comb }}$.

The results show that the combination of features extracted via the fractal analysis and time domain methodologies provides the highest robustness in the overall ANN prediction performance for drilling condition $2700 \mathrm{rpm}-0.11 \mathrm{~mm} / \mathrm{rev}$, yielding a best overall RMSE equal to 0.00032 and an average RMSE equal to 0.00113 (Table 2 and Figure 17b). This confirms the robustness of sensor fusion technology [37] for smart decision making in multi-sensor process monitoring applications [38].

\section{Conclusions}

Smart multi-sensor monitoring of CFRP/CFRP laminate stack drilling for aeronautical assembly was carried out based on thrust force and torque signal detection and analysis for the on-line evaluation of tool wear state. Different signal-processing methods were utilised to extract and select relevant signal features from sensor signals in the time domain, in the frequency domain, and using fractal analysis. The selected signal features were combined into diverse feature pattern vectors, FPV, and utilised as input in an ANN-based machine-learning paradigm to make smart decisions about the timely execution of tool change on the basis of tool wear level estimation. For all CFRP/CFRP laminate stack drilling conditions, very accurate and robust ANN predictions of residual tool life were achieved utilizing the signal features selected on the basis of their correlation with tool wear level. In particular, the fractal analysis and the time domain FPVs provided the best ANN performance in the classification of tool wear level. Therefore, to verify the robustness of smart tool wear curve reconstruction, sensor fusion pattern vectors obtained combining features extracted via fractal analysis and time-domain methodologies were constructed and employed for ANN learning and testing. The best overall ANN prediction was achieved by these FPVs confirming the robustness of sensor fusion technology for smart decision making in multi-sensor process-monitoring applications.

The utilized smart multi-sensor monitoring procedure can thus be reliably employed for on-line tool wear diagnosis aimed at end-of-tool-life dependable forecast required to implement an effective process automation in composite material parts assembly based on mechanical drilling. In this framework, a condition-based tool replacement strategy can be adopted instead of a time-based strategy, accomplishing the enhancement of productivity together with the reduction of scrap rate and tool cost in CFRP/CFRP stack-drilling processes for aeronautical assembly.

Author Contributions: Conceptualization, R.T.; methodology, A.C.; validation, T.S.; investigation, L.N.; data curation, T.S.; supervision, R.T. All authors have read and agreed to the published version of the manuscript.

Funding: This research received no external funding.

Acknowledgments: The Fraunhofer Joint Laboratory of Excellence on Advanced Production Technology (Fh J_LEAPT UniNaples) at the Department of Chemical, Materials and Industrial Production Engineering, University of Naples Federico II, is gratefully acknowledged for its contribution and support to this research activity.

Conflicts of Interest: The authors declare no conflict of interest.

\section{References}

1. M'Saoubi, R.; Axinte, D.; Soo, S.L.; Nobel, C.; Attia, H.; Kappmeyer, G.; Engin, S.; Sim, W.-M. High performance cutting of advanced aerospace alloys and composite materials. CIRP Ann. Manuf. Technol. 2015, 64, 557-580. [CrossRef]

2. Teti, R. Machining of composite materials. CIRP Ann. Manuf. Technol. 2002, 51, 611-634. [CrossRef]

3. Rajak, D.K.; Pagar, D.D.; Menezes, P.L.; Linul, E. Fiber-reinforced polymer composites: Manufacturing, properties, and applications. Polymers 2019, 11, 1667. [CrossRef] [PubMed]

4. Liu, D.; Tang, Y.; Cong, W.L. A review of mechanical drilling for composite laminates. Compos. Struct. 2012, 94, 1265-1279. [CrossRef]

5. Davim, J.P. Machining Composites Materials; John Wiley \& Sons: Hoboken, NJ, USA, 2013.

6. Brinksmeier, E.; Fangmann, S.; Rentsch, R. Drilling of composites and resulting surface integrity. CIRP Ann. Manuf. Technol. 2011, 60, 57-60. [CrossRef] 
7. Jinyang, X.; Chao, L.; Sipei, M.; Qinglong, A.; Ming, C. Study of drilling-induced defects for CFRP composites using new criteria. Compos. Struct. 2018, 201, 1076-1087.

8. Geng, D.; Liu, Y.; Shao, Z.; Lu, Z.; Cai, J.; Li, X.; Jiang, X.; Zhang, D. Delamination formation, evaluation and suppression during drilling of composite laminates: A review. Compos. Struct. 2019, 216, 168-186. [CrossRef]

9. Caprino, G.; Tagilaferri, V. Damage developments in drilling glass fiber reinforced plastics. Int. J. Mach. Tools Manuf. 1995, 35, 817-829. [CrossRef]

10. Cheng, L.; Tian, G.Y. Surface crack detection for carbon fiber reinforced plastic (CFRP) materials using pulsed eddy current thermography. IEEE Sens. J. 2011, 11, 3261-3268. [CrossRef]

11. Yi, Q.; Tian, G.Y.; Malekmohammadi, H.; Zhu, J.; Laureti, S.; Ricci, M. New features for delamination depth evaluation in carbon fiber reinforced plastic materials using eddy current pulse-compression thermography. NDT E Int. 2019, 102, 264-273.

12. Fleischer, J.; Teti, R.; Lanza, G.; Mativenga, P.; Möhring, H.; Caggiano, A. Composite materials parts manufacturing. CIRP Ann. Manuf. Technol. 2018, 67, 603-626. [CrossRef]

13. Al-Wandi, S.; Ding, S.; Mo, J. An approach to evaluate delamination factor when drilling carbon fiber-reinforced plastics using different drill geometries: Experiment and finite element study. Int. J. Adv. Manuf. Technol. 2017, 93, 4043-4061. [CrossRef]

14. Geier, N.; Davim, J.P.; Szalay, T. Advanced cutting tools and technologies for drilling carbon fibre reinforced polymer (CFRP) composites: A review. Compos. Part A Appl. Sci. Manuf. 2019, 125, 105552. [CrossRef]

15. Melentiev, R.; Priarone, P.C.; Robiglio, M.; Settineri, L. Effects of tool geometry and process parameters on delamination in CFRP drilling: An overview. Procedia CIRP 2016, 45, 31-34. [CrossRef]

16. Franke, V. Drilling of long fiber reinforced thermoplastics-Influence of the cutting edge on the machining results. CIRP Ann. 2011, 60, 65-68. [CrossRef]

17. Shyha, I.; Soo, S.L.; Aspinwall, D.; Bradley, S. Effect of laminate configuration and feed rate on cutting performance when drilling holes in carbon fibre reinforced plastic composites. J. Mater. Process. Technol. 2010, 210, 1023-1034. [CrossRef]

18. Geier, N.; Szalay, T.; Takács, M. Analysis of thrust force and characteristics of uncut fibres at non-conventional oriented drilling of unidirectional carbon fibre-reinforced plastic (UD-CFRP) composite laminates. Int. J. Adv. Manuf. Technol. 2019, 100, 3139-3154. [CrossRef]

19. Lissek, F.; Tegas, J.; Kaufeld, M. Damage quantification for the machining of CFRP: An introduction about characteristic values considering shape and orientation of drilling-induced delamination. Procedia Eng. 2016, 149, 2-16. [CrossRef]

20. Caggiano, A.; Napolitano, F.; Nele, L.; Teti, R. Multiple sensor monitoring for tool wear forecast in drilling of CFRP/CFRP stacks with traditional and innovative drill bits. Procedia CIRP 2018, 67, 404-409. [CrossRef]

21. Hocheng, H.; Tsao, C.C. Comprehensive analysis of delamination in drilling of composite materials with various drill bits. J. Mater. Process. Technol. 2003, 140, 335-339. [CrossRef]

22. Saoudi, J.; Zitoune, R.; Mezlini, S.; Gururaja, S.; Seitier, P. Critical thrust force predictions during drilling: Analytical modeling and X-ray tomography quantification. Compos. Struct. 2016, 153, 886-894. [CrossRef]

23. Hocheng, H.; Tsaom, C.C. The path towards delamination-free drilling of composite materials. J. Mater. Process. Technol. 2005, 167, 251-264. [CrossRef]

24. Ahmad, J. Machining of Polymer Composites; Springer: Boston, MA, USA, 2009.

25. Rawat, S.; Attia, H. Characterization of the dry high speed drilling process of woven composites using Machinability Maps approach. CIRP Ann. Manuf. Technol. 2009, 58, 105-108. [CrossRef]

26. Tool-Life Testing with Single-Point Turning Tools; ISO 3685:1993; International Organization for Standardization (ISO): Geneva, Switzerland, 1993.

27. Caggiano, A.; Centobelli, P.; Nele, L.; Teti, R. Multiple sensor monitoring in drilling of CFRP/CFRP stacks for cognitive tool wear prediction and product quality assessment. Procedia CIRP 2017, 62, 3-8. [CrossRef]

28. Bonnet, C.; Poulachon, G.; Rech, J.; Girard, Y.; Costes, J.P. CFRP drilling: Fundamental study of local feed force and consequences on hole exit damage. Int. J. Mach. Tools Manuf. 2015, 94, 57-64. [CrossRef]

29. Karpat, Y.; Bahtiyar, O.; Deger, B.; Kaftanoğlu, B. A mechanistic approach to investigate drilling of UD-CFRP laminates with PCD drills. CIRP Ann. Manuf. Technol. 2014, 63, 81-84. [CrossRef]

30. Mandelbrot, B.B. The Fractal Geometry of Nature; W. H. Freeman: San Francisco, CA, USA, 1982; p. 57.

31. Russ, J.C. Fractal geometry in engineering metrology. In Metrology and Properties of Engineering Surfaces; Mainsah, E., Greenwood, J.A., Chetwynd, D.G., Eds.; Springer: Boston, MA, USA, 2001. 
32. Saghi, Z.; Xu, X.; Möbus, G. Three-dimensional metrology and fractal analysis of dendritic nanostructures. Phys. Rev. 2008, 78, 205428. [CrossRef]

33. Caggiano, A.; Rimpault, X.; Teti, R.; Balazinski, M.; Chatelain, J.F.; Nele, L. Machine learning approach based on fractal analysis for optimal tool life exploitation in CFRP composite drilling for aeronautical assembly. CIRP Ann. 2018, 67, 483-486. [CrossRef]

34. Alpaydin, E. Introduction to Machine Learning; MIT Press: Cambridge, MA, USA, 2014.

35. Bishop, C.M. Pattern Recognition and Machine Learning; Springer: New York, NY, USA, 2006.

36. Jordan, M.I.; Bishop, C.M. Neural Networks. In Computer Science Handbook, 2nd ed.; Tucker, A.B., Ed.; Chapman \& Hall/CRC Press LLC: Boca Raton, FL, USA, 2004.

37. Mitchell, H.B. Multi-Sensor Data Fusion; Springer: Berlin/Heidelberg, Germany, 2007.

38. Segreto, T.; Teti, R. Machine learning for in-process end-point detection in robot-assisted polishing using multiple sensor monitoring. Int. J. Adv. Manuf. Technol. 2019, 103, 4173-4187. [CrossRef]

(C) 2020 by the authors. Licensee MDPI, Basel, Switzerland. This article is an open access article distributed under the terms and conditions of the Creative Commons Attribution (CC BY) license (http://creativecommons.org/licenses/by/4.0/). 